\title{
Chondrite Shock Metamorphism History Assessed by Non-Destructive Analyses on Ca-Phosphates and Feldspars in the Cangas de Onís Regolith Breccia
}

\author{
Alvaro Rubio-Ordóñez ${ }^{1, * \mathbb{C}}$, Olga García-Moreno ${ }^{1} \mathbb{D}$, Luis Miguel Rodríguez Terente ${ }^{2}$, \\ Javier García-Guinea ${ }^{3}$ and Laura Tormo ${ }^{3}$ \\ 1 Departamento de Geología, Universidad de Oviedo, C/Jesús Arias de Velasco s/n, 33005 Oviedo, Spain \\ 2 Museo de Geología, Universidad de Oviedo, C/Jesús Arias de Velasco s/n, 33005 Oviedo, Spain \\ 3 Departamento de Geología, Museo Nacional de Ciencias Naturales (MNCN-CSIC), C/José Gutiérrez Abascal \\ 2, 28006 Madrid, Spain \\ * Correspondence: rubioalvaro@uniovi.es
}

Received: 21 February 2019; Accepted: 3 July 2019; Published: 9 July 2019

\begin{abstract}
The Cangas de Onís regolith breccia is an H5-H6 ordinary chondrite that fell to Earth in 1866. It is constituted by $60 \% \mathrm{H} 6-\mathrm{H} 5$ clasts within an $\mathrm{H} 5$ clastic matrix. All clasts are affected by intense fissuration, with an intricate pattern filled by kamacite and troilite, shock metamorphism of plagioclase into maskelynite. The chondrite is composed of low-Ca pyroxene, olivine and plagioclase as the main silicate phases, with two types of phosphates, taenite-kamacite blebs and troilite. The specimen was studied by micro-Raman spectroscopy, Fourier-transform infrared spectrophotometry (FTIR), spectral cathodoluminescence and computer tomography. The ease with which the specimens can be prepared for analysis using these techniques, and the speed with which relevant information can be obtained, make them excellent tools for the study of non-replaceable materials. Moreover, the Raman and FTIR results offer enough resolution to reveal heterogeneities in the shocked metamorphism throughout the specimen. The obtained results showed that the extent of the metamorphic conditions within the studied sample is heterogeneous, which leads us to believe that the last accretionary event that took place in this regolithic breccia was not significant enough to allow for overall homogenization.
\end{abstract}

Keywords: chondrite; raman; FTIR; non-destructive; chlorapatite; merrillite; maskelynite

\section{Introduction}

Non-destructive evaluation methods usually include different spectroscopy techniques to analyze both the surface and the interior of the objects under study. In museums, there are valuable stones such as meteorites that have had to be sliced in order to make polished petrographic sections with which to perform characterization studies. The application of non-destructive techniques makes it possible to perform practical studies while preserving these non-replaceable materials.

New experimental data obtained using Raman spectroscopy of phosphates has opened the door to important petrogenetic data from these minerals. The position of the main phosphate peaks in Raman emissions is related to pressure in tuite and other orthophosphates in static pressure experiments [1-6]. In the same way, there are numerous studies that relate the morphology of the absorption spectra obtained by Raman and micro-FTIR in feldspars and other minerals to their pressure conditions [7-12]. These studies with high pressure phases (not founded in Cangas de Onis) can be useful to determine the spectral changes in our phases (related with shock metamorphism effects). Moreover, recent work has reassessed the classification of chondrites based on shock metamorphism, by more precisely redefining the characteristics of meteorites with greater metamorphism (types S5 and S6) [13]. 


\section{Cangas de Onís Meteorite}

The University of Oviedo Geology Museum holds three fragments of the Cangas de Onís regolith breccia. This meteorite fell in Cangas de Onís (Asturias, Spain) on December 6, 1866, and several fragments were recovered. Recently, nine new fragments that have not been referenced until now were recognized in a donation from a private collector. This meteorite has been studied and characterized by different authors [14-19]. The Cangas de Onís regolith breccia is an H5-H6 ordinary chondrite, with approximately $60 \%$ of its makeup consisting of $\mathrm{H} 6$ and $\mathrm{H} 5$ clasts within an $\mathrm{H} 5$ clastic matrix. Mineralogically, all of the fragments are similar, being constituted by low-Ca pyroxene, olivine and plagioclase with kamacite, taenite and troilite as the main phases. Phosphates are common, and two different phosphates have been identified, chlorapatite and merrillite. Clasts in the breccia are affected by intense fissuration caused by shock. These fractures are partially filled by kamacite and/or troilite. The parental body was affected by an impact at least $7 \mathrm{Ma}$ ago, when it left its stable orbit $[15,16]$.

Previous studies [17-19] have concluded that the Cangas de Onís regolith breccia had suffered at least two processes of accretion and destruction with associated shock metamorphism and partial melting of silicates and metallic minerals. The present study, however, is the first to use non- destructive techniques to trace the shock-metamorphic history of a chondrite regolith breccia. Here, we have performed a complete analysis of the breccia's phosphates (chlorapatite and merrillite) and feldspars (plagioclase and maskelynite) through an array of non-destructive techniques (X-Ray Computerized Tomography Scan, Back-scattered electron images (BSE), Cathodoluminescence (CL), RAMAN spectroscopy and Fourier Transform Infrared (FTIR) spectrophotometry).

Although the effects of shock metamorphism are best studied in tectosilicates (mainly quartz and feldspars), we have found that these effects can also be detected in Ca-phosphates. After the characterization and classification of phosphates and feldspars in the Cangas de Onís regolith breccia, we analyzed the Raman and FTIR spectra of these phosphates together with the feldspar phases, to determine relative pressure conditions in different clasts within the Cangas de Onís breccia related to shock metamorphism.

\section{Materials and Methods}

Data for the electron microscopy studies were collected at the physical-chemical facilities of the Museo Nacional de Ciencias Naturales, in Madrid (Spain). The environmental electron microscopy studies were performed using an FEI Inspect environmental scanning electron microscope (ESEM). The samples were observed with the BSE, energy dispersive Spectroscopy (EDS) and large field (LF) detectors. The ESEM resolution at low vacuum was $4.0 \mathrm{~nm}$ at $30 \mathrm{kV}$ (BS). The accelerating voltage was $200 \mathrm{~V}$ to $30 \mathrm{kV}$ and the probe current up to $2 \mu \mathrm{A}$ was continuously adjusted, with low vacuum $0.45-0.55$ torr, and a working distance of $10 \mathrm{~mm}$. Sample EDS and mapping areas were carried out with an energy dispersive X-ray spectrometer (Oxford Instruments INCA Energy 200 Energy Dispersive System).

The Inspect ESEM has a new coupled MonoCL3 Gatan probe to record CL spectra and panchromatic and monochromatic plots. It has a PA-3 photomultiplier tube covering a spectral range of $185-850 \mathrm{~nm}$, which is more sensitive in the blue parts of the spectrum. A retractable parabolic diamond mirror and a photomultiplier tube were used to collect and amplify luminescence. The sample was positioned $16.2 \mathrm{~mm}$ beneath the bottom of the CL mirror assembly. The excitation for CL measurements was provided at $25 \mathrm{kV}$ by an electron beam. 
In the same laboratory we obtained the micro-Raman and photoluminescence spectra of the spot samples. We used a Thermo-Fischer DXR Raman Microscope. The system has an Olympus BX-RLA2 Microscope and a Charge Coupled Device (CCD) detector $(1024 \times 256$ pixels), motorized XY stage, auto-focus and Olympus UIS2 series microscope lenses, all controlled through OMNIC 1.0 software (version 1.0.0.0, Thermo-Fischer Scientific Inc., Waltharn, MA, USA). The light at $532 \mathrm{~nm}$ of a frequency doubled Nd:YVO4 diode-pumped solid-state (DPSS) solid laser (maximum power $30 \mathrm{~mW}$ ) was used for excitation. The DRX Raman has a point-and-shoot Raman capability of one-micron spatial resolution. We used the 20x objective of the confocal microscope together with the laser source at $532 \mathrm{~nm}$ and 6 $\mathrm{mW}$ in laser mode, with power at $100 \%$. The average spectral resolution in the Raman shift ranging from 100 to $3600 \mathrm{~cm}^{-1}$ was $4 \mathrm{~cm}^{-1}$, i.e., grating 900 lines $/ \mathrm{mm}$ and $2 \mu \mathrm{m}$ spot sizes. The system was operated under OMNIC 1.0 software, setting working conditions such as pinhole aperture of $25 \mu \mathrm{m}$, a bleaching time of $30 \mathrm{~s}$, and four exposures with an average time of $10 \mathrm{~s}$ each.

Infrared reflectance spectra were also obtained at the Servicios Científico-Técnicos of the University of Oviedo (Spain), using an FTIR spectrophotometer coupled to a Varian 620-IR and Varian 670-IR microscope. Analyses were obtained from circular $100 \mu \mathrm{m}$ diameter regions.

Micro-computed tomography (CT) scans were run on the $10.5 \mathrm{~g}$ piece of Cangas meteorite held in the meteorite exhibition hall of the Museo Nacional de Ciencias Naturales (MNCN) of Madrid, in order to observe volume, bulk density, and variations in internal density. For the volume and bulk density measurements we used a Nikon X-Tek CT-Scan device, also located at the MNCN laboratories, with a peak X-ray voltage of $146 \mathrm{kV}$ and current of $65 \mathrm{~mA}$, collecting 1583 sections at 1000 micro-seconds, being each section the average of four frames. The system operates with a tungsten $\mathrm{X}$-ray tube and added filtration $(0.875 \mathrm{~mm} \mathrm{Cu})$ to reduce beam hardening. Three- dimensional viewings and analyses of the obtained X-ray sections were performed using the program VG Studio Max Version 2.2. The auto-threshold feature determined the gray-scale intensity for 3-D surface segmentation and subsequent analysis. Surface reconstruction is useful for determining the volume and for correlating surface features with interior areas of interest.

Microprobe data were also obtained for phosphates and feldspars from the meteorite. Analytical procedure and chemical data see Supplementary Tables S1-S3.

\section{Results}

The detailed BSE-SEM images on the studied sample are shown in Figure 1. In this process we recognized and measured all phosphates present in the thin section, identifying every phosphate grain in each breccia clast. The results indicate that the size of the phosphate crystals is variable. In addition, it depends on the clasts where they can be found. The largest phosphate crystals are found in the matrix $(202 \mu \mathrm{m} \times 122 \mu \mathrm{m})$, while the phosphates in the clasts are smaller (clast 1, $144 \mu \mathrm{m} \times 9 \mu \mathrm{m}$; clast 2, $93 \mu \mathrm{m}$ $\times 68 \mu \mathrm{m}$; clast 3, $91 \mu \mathrm{m} \times 52 \mu \mathrm{m}$; clast 4, $63 \mu \mathrm{m} \times 45 \mu \mathrm{m}$ ). Moreover, the size of the phosphate crystals is independent of the phosphate type. In the same areas as the phosphates, we likewise recognized and located all of the feldspars present. These crystals have variable sizes and are characterized by allotriomorphic morphologies, with micro-inclusions of olivine and pyroxene, and crosscut by Fe-Ni and troilite veins. 

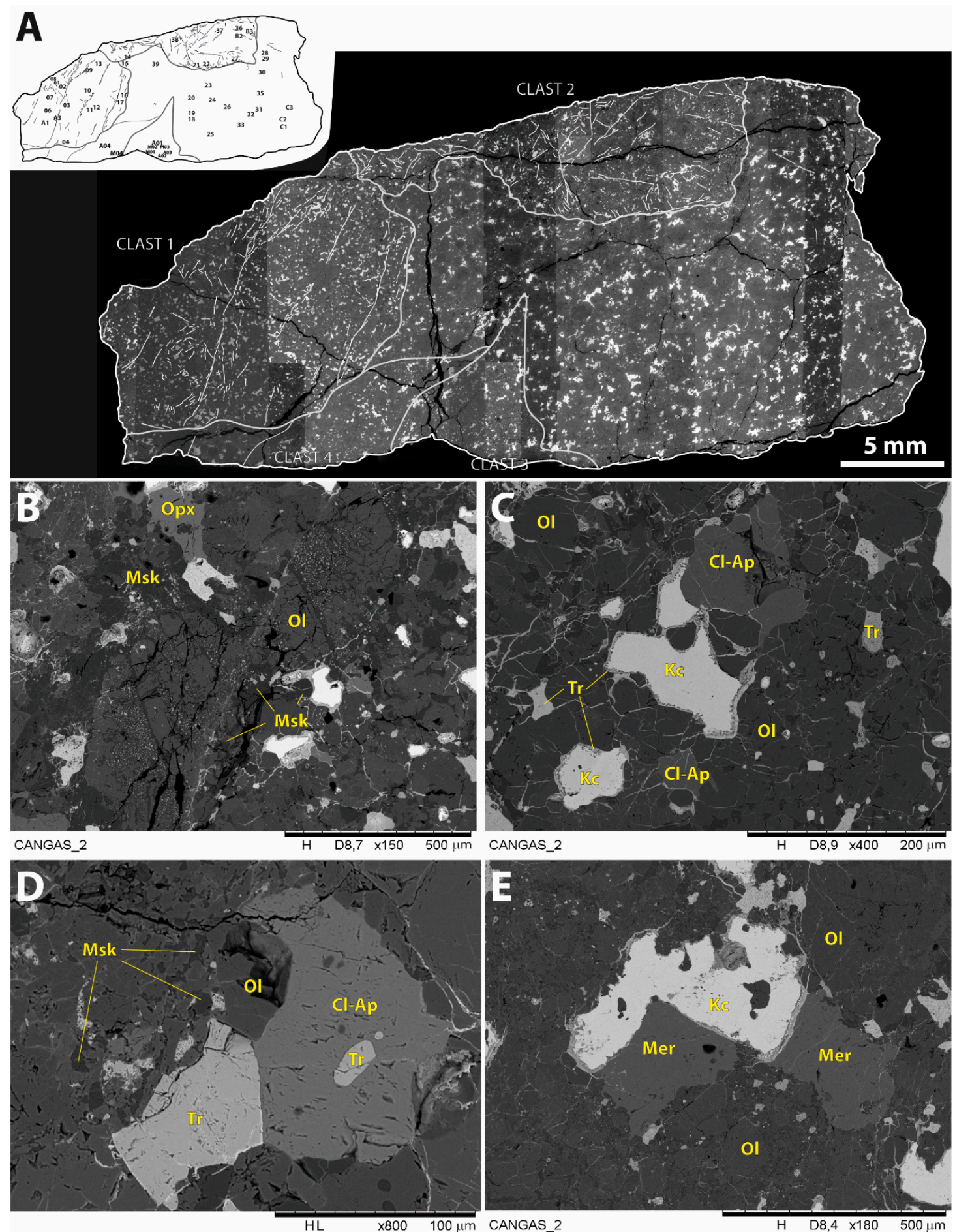

Figure 1. Scanning electron images of the sample (A) Image photomontage of the analyzed sample surface. Position of analyzed fields and main clasts are schematized in the upper left inset. (B) Shock-melted fracture in field 17 (Clast 1), affecting an olivine chondrule. (C) Textural features of analyzed phosphates in Clast 3 (field A04). (D) Chlorapatite in Clast 2 (field 38). (E) Merrillite over kamacite partially affected by shocked veins of troilite. Opx: Orthopyroxene; Msk: Maskelynite; Ol: Olivine; Tr: Troilite; Kc: Kamacite; Mer: Merrillite; Cl-Ap: Clorapatite.

\subsection{Computerized Tomography Scan}

Orthogonal cross-sections of the micro-CT images displayed high-density regions, demonstrating heterogeneities in mineral distribution. High atomic number features, such as metallic grains, coincide 
with bright voxels on micro-CT images, whereas the silicate matrix appears as a darker gray medium. The Cangas fragment in Figure 2, for instance, does not exhibit a preferential distribution of metallic grains, which is consistent with the external observation of the fragment's surfaces.
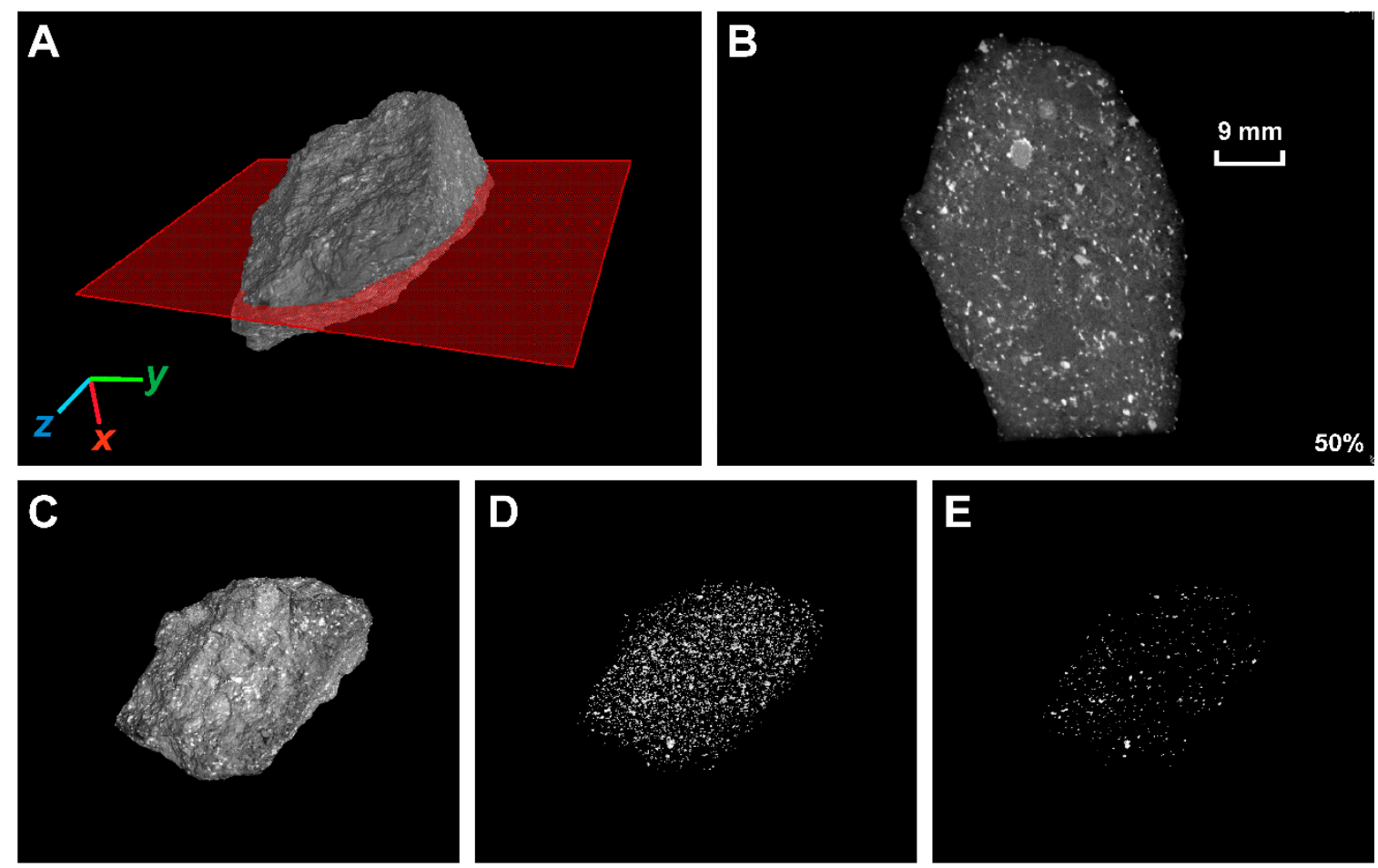

Figure 2. (A,B) CT scan display of a section in which the whitest grains are Fe-Ni, pale grey is troilite, intermediate grey is iron-silicates, and darker areas are plagioclase. The CT scan technique offers similar images in quality to those obtained by backscattering, with the added benefit of being able to observe an internal section using a non-destructive technique. (C-E) show section visualizations with different grades of density filter; in all probability the last image (E) corresponds to a plot of the spatial distribution of Fe-Ni masses.

\subsection{Cathodoluminescence Spectral Study}

The cathodoluminescence (CL) study of both types of phosphates, chlorapatite and merrillite, reveals two totally different spectra (Figure 3). In the case of chlorapatite (Figure 3A), the CL spectra are constituted by a relatively wide peak at $582 \mathrm{~nm}$ related to the presence of $\mathrm{Mn}^{2+}$ as a luminescence emission activator. Less significant peaks show up at around 382 and $474 \mathrm{~nm}$, and are related to the presence of minor quantities of REE and intrinsic luminescence. In the case of merrillite (Figure 3B), the obtained spectra are more complicated, with several peaks at different positions. There are at least three main peaks, at 344, 365 and $572 \mathrm{~nm}$, the last one being related to the presence of $\mathrm{Mn}^{2+}$ as an activator, and the others probably related to REE or to intrinsic luminescence. The rest of the peaks may be related to variable quantities of REE elements. However, the width and the relative intensity of the peaks are totally different from those of chlorapatite. There are no substantial differences in the individual CL spectra for each phosphate type. 

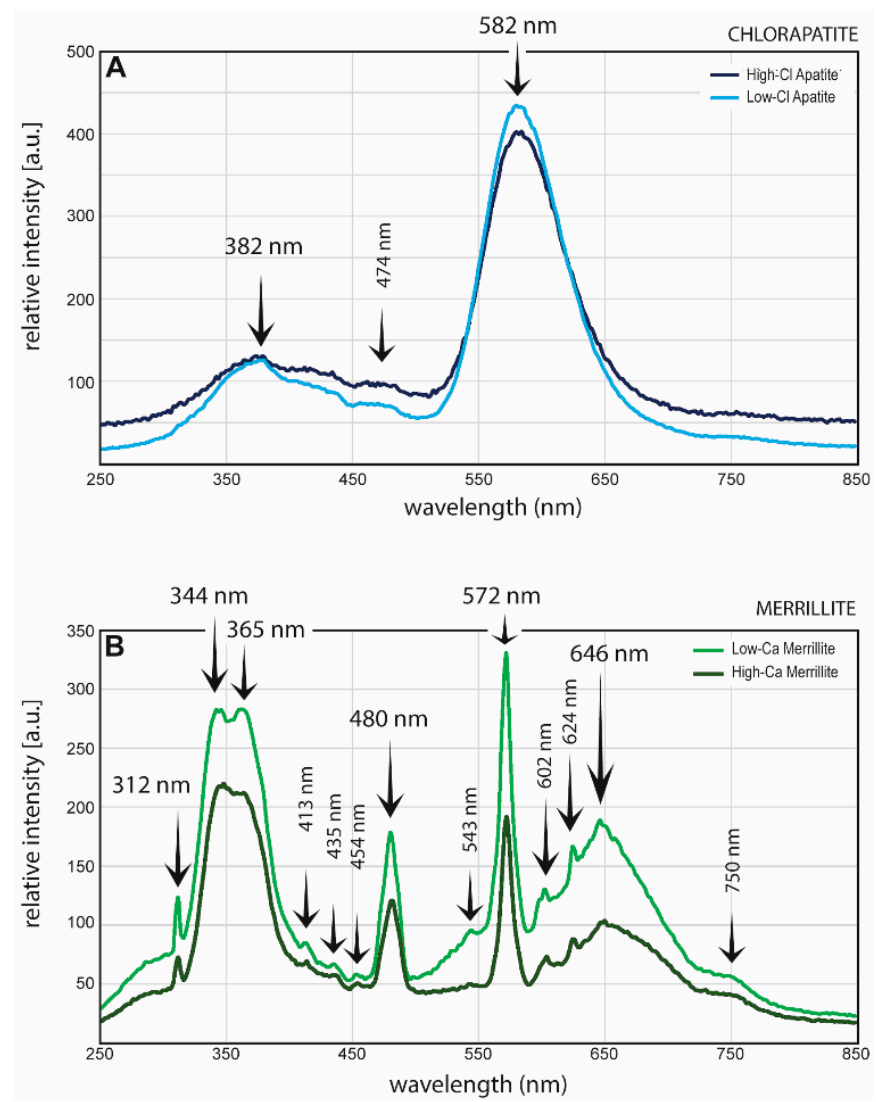

Figure 3. Cathodoluminescence spectra of the two distinct phosphates. (A) Chlorapatite, high and low chlorine-content types, and (B) merrillite, high and low calcium content.

Feldspars exhibited no differences throughout the spectra collected via CL. The presence of two peaks of similar intensity at 436 and $466 \mathrm{~nm}$ is characteristic of all feldspar spectra, and therefore will not be examined in this paper.

\subsection{Raman}

\subsubsection{Phosphates}

A systematic study of the Raman spectra of the phosphates was conducted on the Cangas sample. The results show that there are two different main spectra, one characteristic of chlorapatite and the other corresponding to merrillite (Figure 4). The spectra are characterized by the presence of large Raman peaks around 956 and $972 \mathrm{~cm}^{-1}$ in merrillites and only ca. $958 \mathrm{~cm}^{-1}$ in chlorapatites. These bands are produced by the $v 1$ symmetric stretching mode of $\left(\mathrm{PO}_{4}\right)^{3-}$. These major bands are accompanied by minor bands between 1000 and $1080 \mathrm{~cm}^{-1}$, which are related to asymmetric $v 3$ vibrations. Minor peaks can be observed at around 550 to $620 \mathrm{~cm}^{-1}$, and are also characteristic of both phosphates $[12,19,20]$. Characteristic bands related to the presence of $\mathrm{OH}^{-}$(near $3600 \mathrm{~cm}^{-1}$; graphical spectra end at $3650 \mathrm{~cm}^{-1}$ ) were not observed in chlorapatite or in merrillite. Moreover, peaks with variable intensity appear in the merrillite spectra between 2050 and $2750 \mathrm{~cm}^{-1}$. These bands were interpreted as photoluminescence of REE, replacing structural $\mathrm{Ca}^{2+}$ in the crystallographic structure of merrillite $[20,21]$. In the case of chloroapatite, no defined peaks can be observed in this region, but a generalized intensity anomaly is usually present in the same area, interpreted by the same mechanism as in the case of merrillite. 

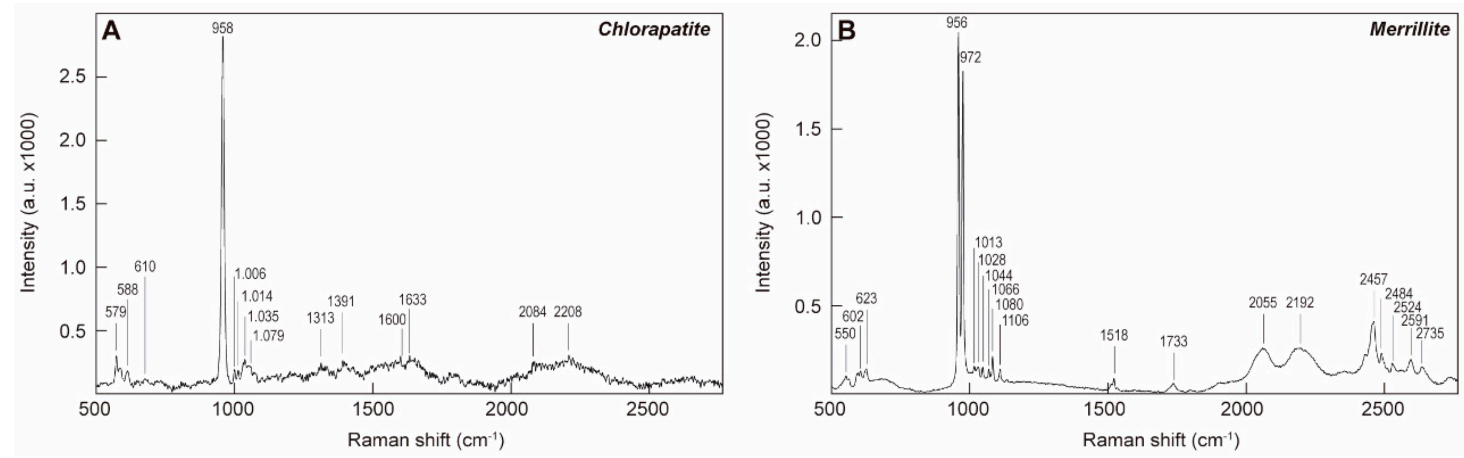

Figure 4. Raman spectra of two phosphate types: (A) Chlorapatite and (B) merrillite.

\subsubsection{Feldspars}

The Raman spectra of the feldspars were also analyzed (Figure 5). The obtained spectra show no differences among the crystals. These spectra are characterized by the presence of two large Raman peaks around 478 and $510 \mathrm{~cm}^{-1}$ (T-O and O-T-O bands), and minor bands at $171 \mathrm{~cm}^{-1}$ (O-T and M-O), 290 to $397 \mathrm{~cm}^{-1}$ (O-T-O and T-O-T bands) and 553 to $686 \mathrm{~cm}^{-1}$. The intensity of all the peaks, together with the spectral positions, is similar to those obtained from shocked plagioclase (e.g., reference [22]). The obtained spectra do not show a substantial presence of $\mathrm{OH}^{-}$in the analyzed feldspar grains, since the Raman spectrum ends in a low slope at $3650 \mathrm{~cm}^{-1}$. Under a laser source at $532 \mathrm{~nm}$, the sample exhibits two additional bands framed in the $2000-3000 \mathrm{~cm}^{-1}$ region, which can be attributable to photoluminescence emission features from the accessorial maskelynite glass.

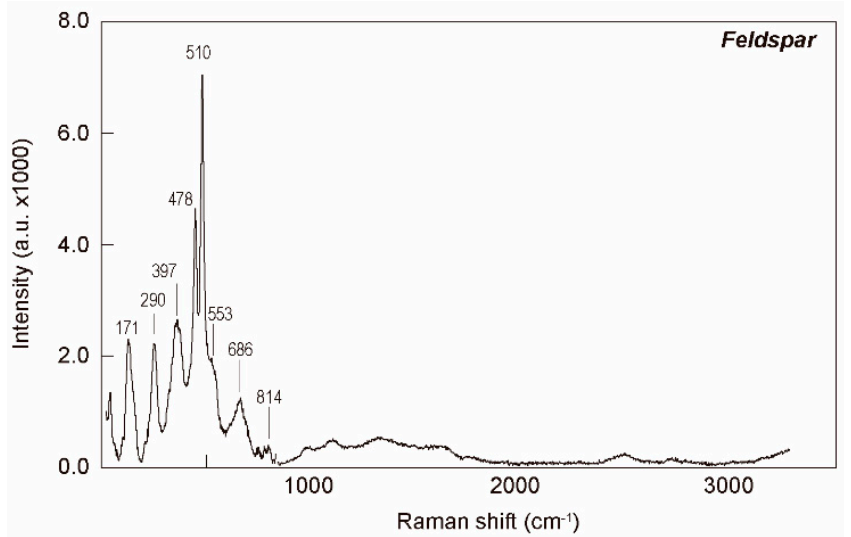

Figure 5. Raman spectra of plagioclase.

\subsection{Fourier Transform Infrared Spectroscopy}

\subsubsection{Phosphates}

A complementary FTIR study was made on the same phosphate grains analyzed by Raman. As in the case of the Raman spectra, two different spectra were observed, one characteristic of Cl-apatite, and the other characteristic of merrillite (Figure 6). Due to the nature of the equipment, all spectra show bands related to the presence of water and $\mathrm{CO}_{2}$ present in the atmosphere (located in the region of 1400-1800, 2300-2400 and 3500-4000 $\mathrm{cm}^{-1}$ ). In the case of Cl-apatite, the FTIR spectra are characterized by one major absorption band at ca. $995 \mathrm{~cm}^{-1}$ and minor bands at 950, 1060 and $1080 \mathrm{~cm}^{-1}$. These bands are related to $v 1$ and $v 3$ stretching mode [23], and are more complex in the case of merrillite. Moreover, based on the intensity of the main peaks, two different spectra can be distinguished for this phase. The first one (type A) has two main peaks at 970 and $1005 \mathrm{~cm}^{-1}$ and a symmetric distribution of intensities with minor peaks at 860,1040,1060, 1080 and $1120 \mathrm{~cm}^{-1}$. In this type of spectra, the asymmetric $v 3$ bands of $\left(\mathrm{PO}_{4}\right)^{3-}$ are more important than the symmetric $v 1$ bands. 
In the second type (type B), the distribution of the peaks is widespread with a main peak at 860 and $920 \mathrm{~cm}^{-1}$, and peaks with less intensities are to be found at 970,1005 and $1120 \mathrm{~cm}^{-1}$. In this case the symmetric $v 1$ bands of $\left(\mathrm{PO}_{4}\right)^{3-}$ are dominant over the $v 3$ asymmetric bands. A minor peak at $730 \mathrm{~cm}^{-1}$ can also be observed in this type of merrillite FTIR spectra. This peak has been interpreted as the symmetric vibration of the bond $\mathrm{P}-\mathrm{O}-\mathrm{P}$ in the $\mathrm{P}_{2} \mathrm{O}_{7}$ [24]. It is possible that these two different spectra were caused by two different structural merrillites. The structural differences can be caused by partial substitutions in the mineral structure [23-26]. At least two samples show transitional spectra between these two main types.

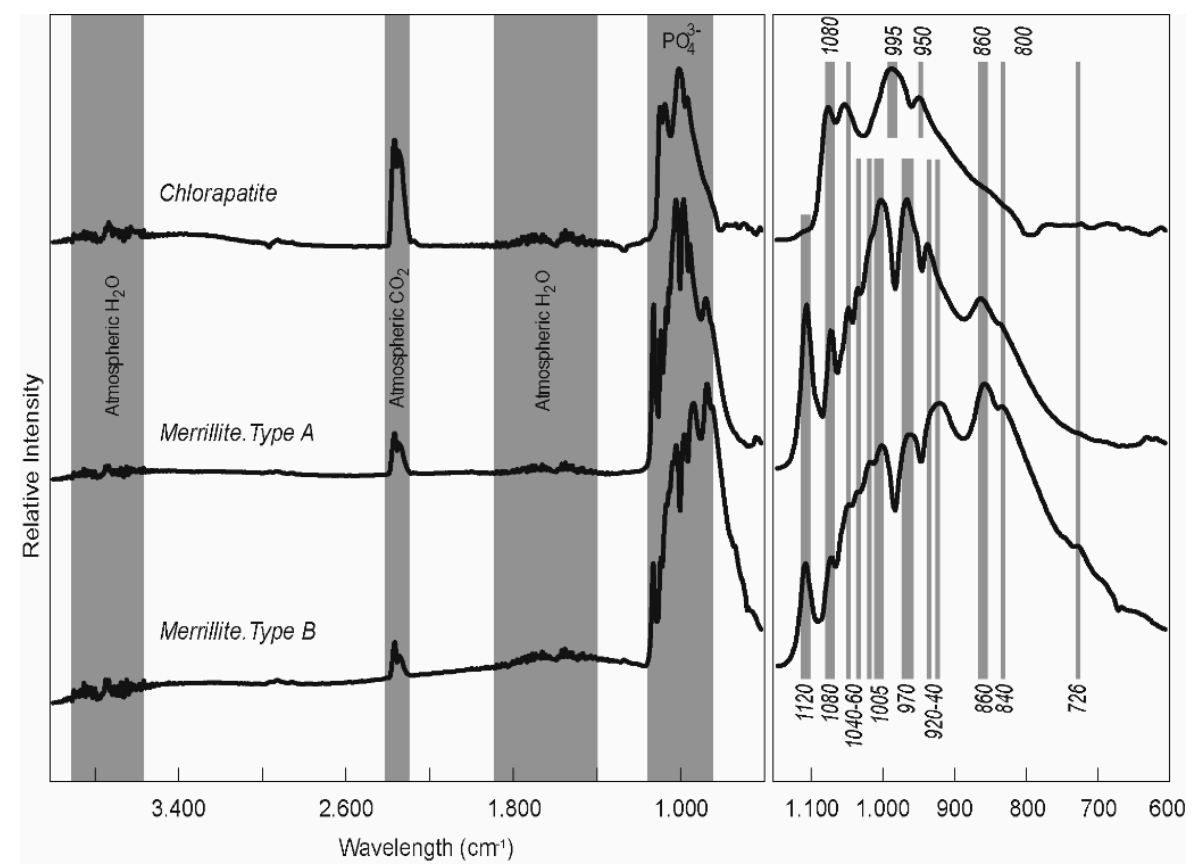

Figure 6. FTIR spectra of chlorapatite and two different types of spectra of merrillite, with bands attributed to atmospheric $\mathrm{H}_{2} \mathrm{O}$ and $\mathrm{CO}_{2}$.

\subsubsection{Feldspars}

As in the case of the phosphates, we analyzed the FTIR spectra of the same feldspar grains that were previously analyzed for Raman (Figure 7). There were some additional difficulties for the feldspar analyses, due to the presence of micro-inclusions of olivine or pyroxene, generating mixed spectra of both minerals. However, the different position of the main peaks, together with the possibility of obtaining inclusion-free crystal analyses on some feldspar, ultimately yielded sound results.

The obtained maskelynite spectra show a typical profile with a wide peak between 930 and $940 \mathrm{~cm}^{-1}$ corresponding to symmetric $v 1 \mathrm{Si}-(\mathrm{Al})-\mathrm{O}$ bands, and smaller bands at 640 that correspond to $\delta \mathrm{O}-\mathrm{Si}(\mathrm{Al})-\mathrm{O}, 720$ and $750 \mathrm{~cm}^{-1}$ (Si-Al(Si) and Si-Si v1 bands) and $1050 \mathrm{~cm}^{-1}$ (e.g., [12]). In those spectra with olivine micro-inclusions there is a narrower main peak at around $940 \mathrm{~cm}^{-1}$, and the minor peaks are much less intense, but the $\delta \mathrm{O}-\mathrm{Si}(\mathrm{Al})-\mathrm{O}$ band is present at $640 \mathrm{~cm}^{-1}$. 


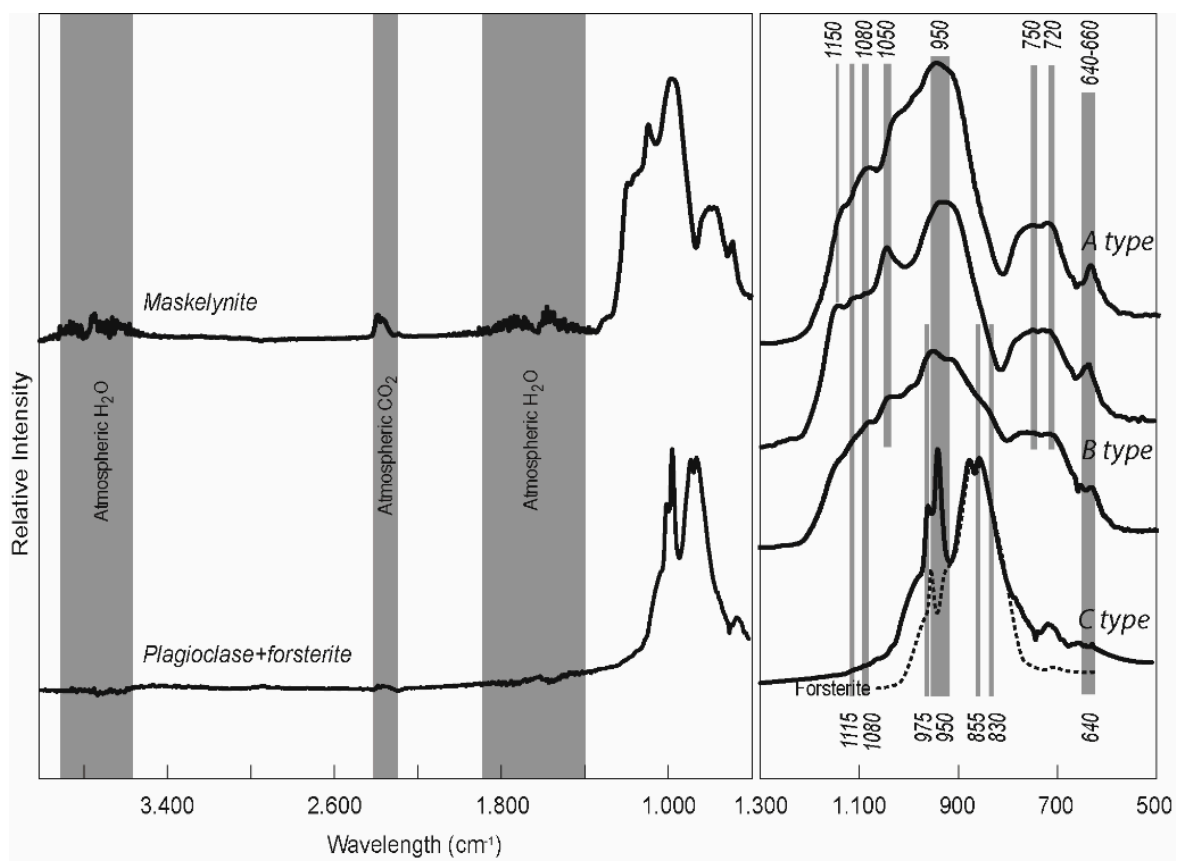

Figure 7. FTIR spectra of maskelynite/plagioclase in three different types, based on peak positions and different grades of crystallinity.

\section{Discussion}

Various studies on the effects of pressure on the crystallization of phosphates $[2-4,26,27]$ have determined that the main peaks in the Raman spectra are displaced to higher values as pressure increases. If we analyze the obtained Raman spectra focusing only on peak position, we can observe a certain degree of variability (Figure $8 \mathrm{~A}, \mathrm{~B}$ ). Peaks at lower positions are found in crystals of chlorapatite and merrillite located in nearby locations in the sample. This observation may be related to different shock metamorphic conditions, with relative minor pressure effects in some clasts when compared with others. Moreover, there is a significant observable effect related to the main shock-melted veins and fractures in the clasts (Figure 9), as Raman spectra peaks in grains close to these fractures show higher displacement values.
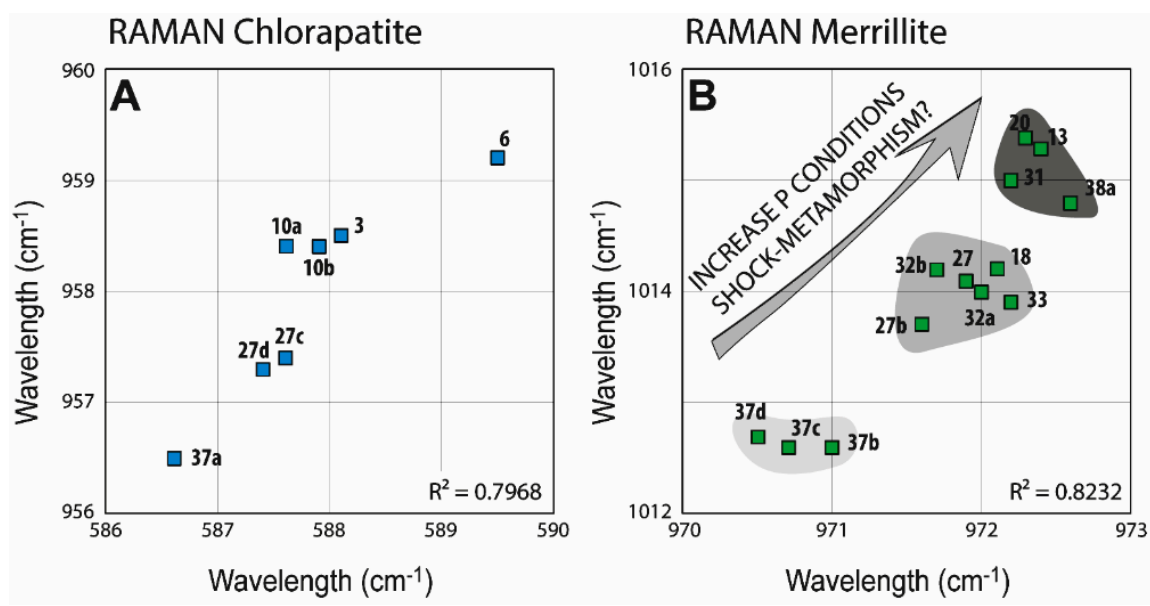

Figure 8. Bivariate diagrams of main peak positions in the Raman spectra, with their correlation coefficients. (A) Raman Cl-apatite peaks. (B) Raman merrillite peaks. 


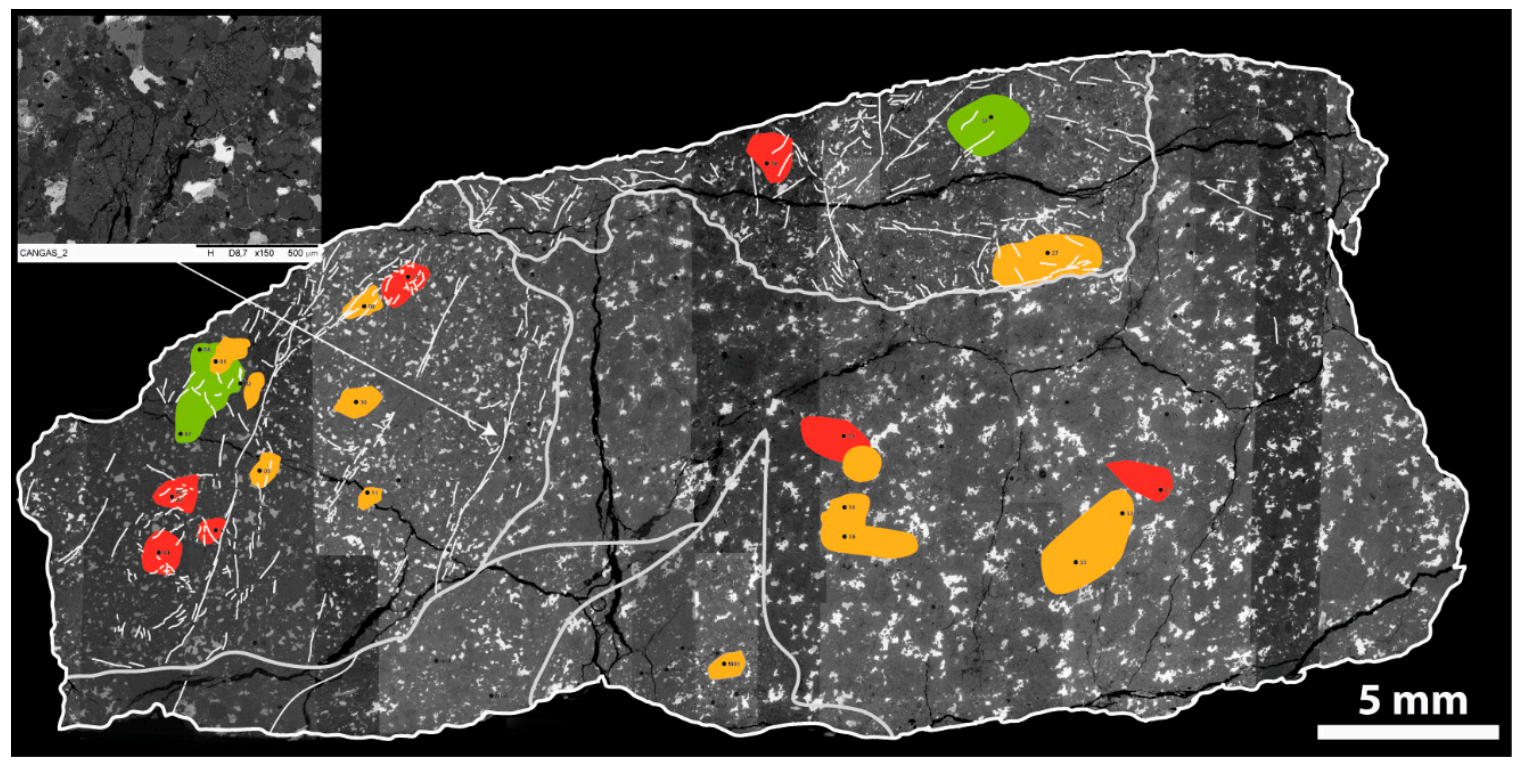

Figure 9. Interpretative scheme of the analyzed probe (same as Figure 1), including clast limits and main shock-melted fractures (e.g., detailed image). An approximate pressure effect deduced from the Raman and FTIR peak positions observed in the phosphates and maskelynite have been included (green, relatively low pressure; orange, intermediate; red, relatively high pressure).

The effect of shock metamorphism in the observed FTIR spectra is more difficult to interpret, as these spectra present a greater degree of uncertainty. Although there is no evidence to support the pressure effect (Figure 10), the peak positions nevertheless appear to be related to certain differences in the spectra. The peak position values in the type-B FTIR spectra samples are lower than in the type-A spectra. Transitional samples, such as 27 or 18, are located between two populations (Figure 11B). The positions with the highest $\mathrm{P}$ conditions according to the Raman peak position diagrams are located in opposite locations in the FTIR peak position diagram (e.g., samples 20 and 13).

FTIR Chlorapatite

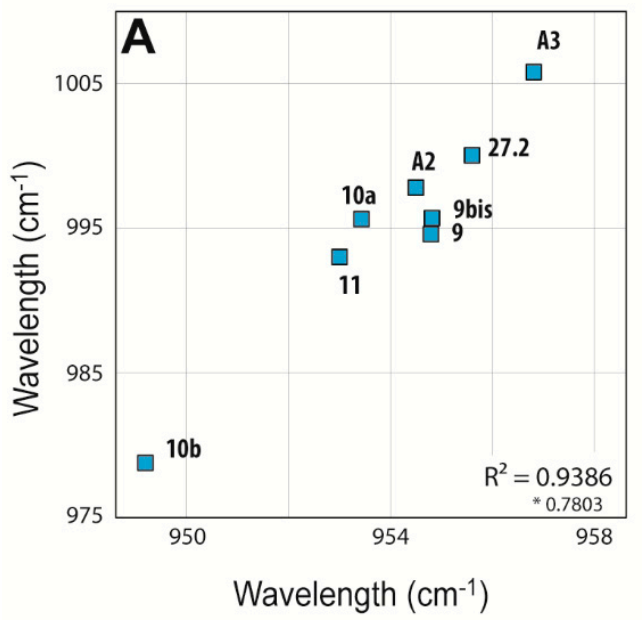

FTIR Merrillite

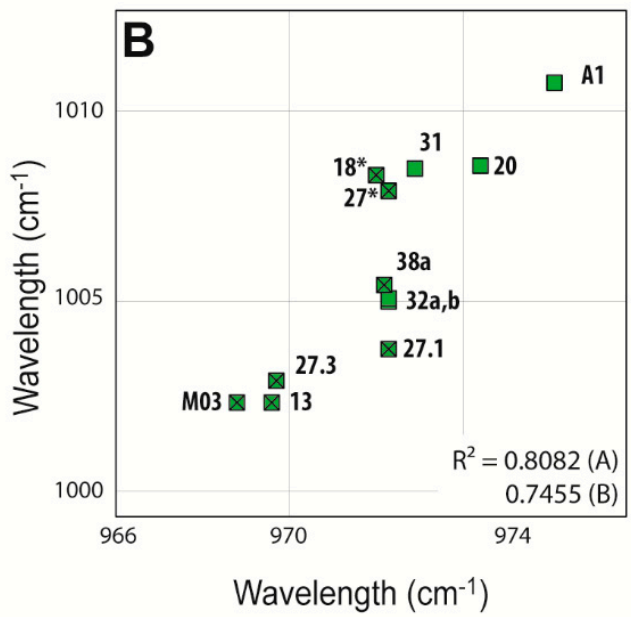

Figure 10. Bivariate diagrams of main peak position in the FTIR spectra, with their correlation coefficients. (A) FTIR Chlorapatite peaks. (B) FTIR merrillite peaks for type-A FTIR spectra (blank squares) and type-B FTIR spectra (crossed-out squares), with their correlation coefficients. 
FTIR Plagioclase

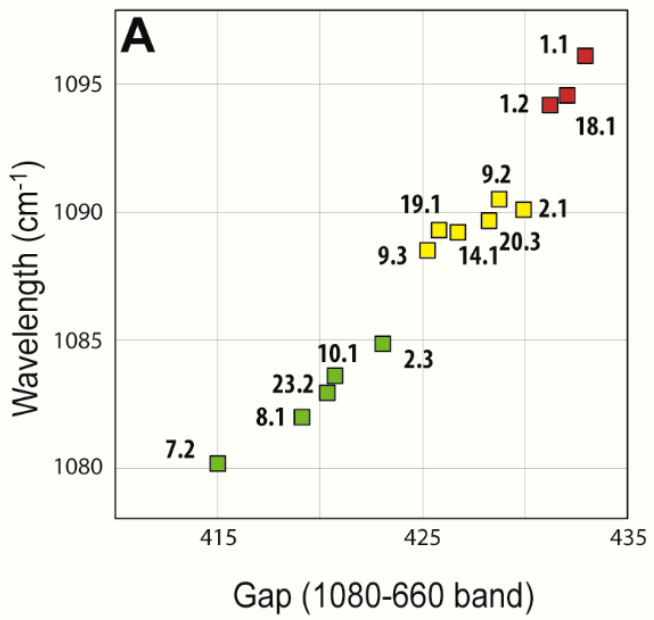

FTIR Plagioclase

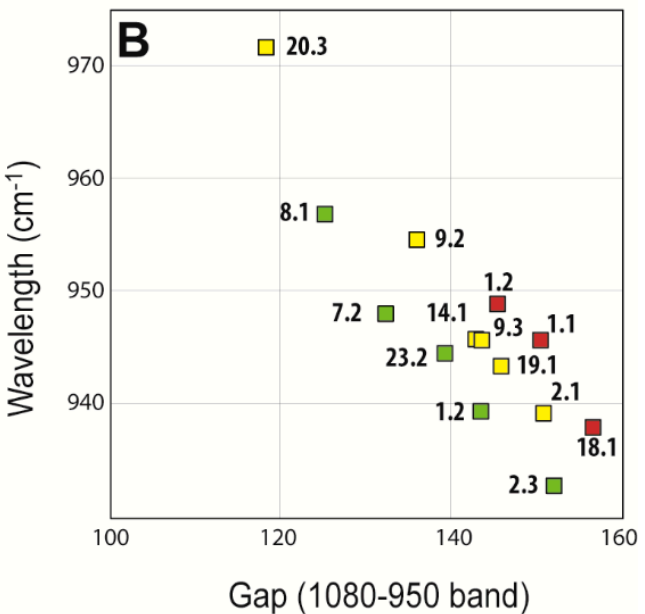

Figure 11. Bivariate diagrams of main peak position in the FTIR spectra, with their correlation coefficients. (A) Bivariate diagram of peak position and the gap between peak bands 1080-660 nm. (B) Bivariate diagram of the same peak position as in A and peak bands 1080-950 nm; green, maskelynite FTIR spectra type A; yellow, maskelynite FTIR spectra type B; red, maskelynite FTIR spectra type C.

The pressure dependence of band position in the Raman and FTIR spectra of feldspars has previously been studied by several authors (e.g., references [28,29]). For example, [28] indicate that the crystallinity of Sr-feldspar decreases as pressure increases, with broader peaks at higher pressure than at lower pressure for micro FTIR. For pressures up to $10 \mathrm{GPa}$, peak positions are modified and move to higher positions, but for pressures above $10 \mathrm{GPa}$ this relationship is reversed. As established in previous studies $[17,19]$, these pressure conditions throughout the Cangas de Onís regolith breccia's history of accretion, disintegration and reaccretion were easily determined. In all likelihood, it was repeated impacts on the surface of the body that formed the regolith [30]. The Cangas de Onís regolith breccia has been classified as type S3 [13,30], according to the presence of melt pockets and opaque shocked veins, but we associate the secondary Raman-PL emission features framed in the 2000-3000 $\mathrm{cm}^{-1}$ region with accessorial maskelynite glass infilling feldspar fissures, since [31] has analyzed hydrogenated vitreous silica by Raman, attributing the spectrum band at $2255 \mathrm{~cm}^{-1}$ to the vibration of $\mathrm{SiH}$ groups.

Through experimentation, we have observed that these bands display full size in recently formed or heated feldspar glass or crystals. The photoluminescence band intensities of the $2000-3000 \mathrm{~cm}^{-1}$ spectral region decrease gradually through time following glass relaxation mechanisms; indeed, the Cangas fragments were heated more than a century ago, which explains this low emission.

The broad FTIR bands observed for feldspars in the Cangas de Onís regolith breccia reflect, in the same way as phosphates (Figure 11A,B), variations that can be correlated to clast type and proximity to shock-melted veins (Figure 9). This correlation, together with the phosphate results, allows us to interpret that the chondritic matrix has relatively higher pressure effects in these two species than in some of the clasts. Moreover, the clasts show variation in these pressure effects that are spatially related to some of the shock-melted veins. In Clast 1 , higher values are associated with two areas related to a shock-melted vein (Figure 9): one in a lower part where a complex fracture pattern developed; and a second area at the end of said shock-melted vein. Lower pressure values are associated with areas where these shock-melted veins are not well developed. The same scheme can be observed in Clast 2 .

This evidence allows us to be more precise in addressing the complex accretional history of the Cangas de Onís regolith breccia. A previous intricate scenario was depicted by [17], with at least two accretion events evidenced by the formation of a breccia within the breccia. In that paper a detailed mineralogical and textural study evidenced the occurrence of several impact events in the formation of the $\mathrm{H}$ Chondrite parent body. One of the last impact events reported by these authors is related to 
the formation of the regolith breccia on the surface of the parent body. Lithification was caused by impact, or additional collisions in space, after the blocks of the breccia had become detached from the parent body.

The data provided in the present paper complete the scenario described by these authors. After the thermal metamorphism into the parental body (around $100 \mathrm{~km}$ of diameter and below $750 \mathrm{~K}$ ), the first process of accretion observed took place under relatively low pressure conditions $(<10 \mathrm{GPa})$, with temperatures below $750 \mathrm{~K}$. During this process, the different grains of taenite and kamacite were formed with a fissural diffusion into the first cracks developed. The different silicates underwent fusion processes after cooling. At some later time, the body or bodies exhibiting these fragments underwent impact rupture, with the formation of shocked veins, cracks and microcracks in the materials, and the phosphates registering an increase in ambient pressure (<10 GPa). Through these fissures, sulfurous vapors penetrated, producing the partial transformation of the taenite-kamacite into pentlandite and troilite (Figure 12A,B).
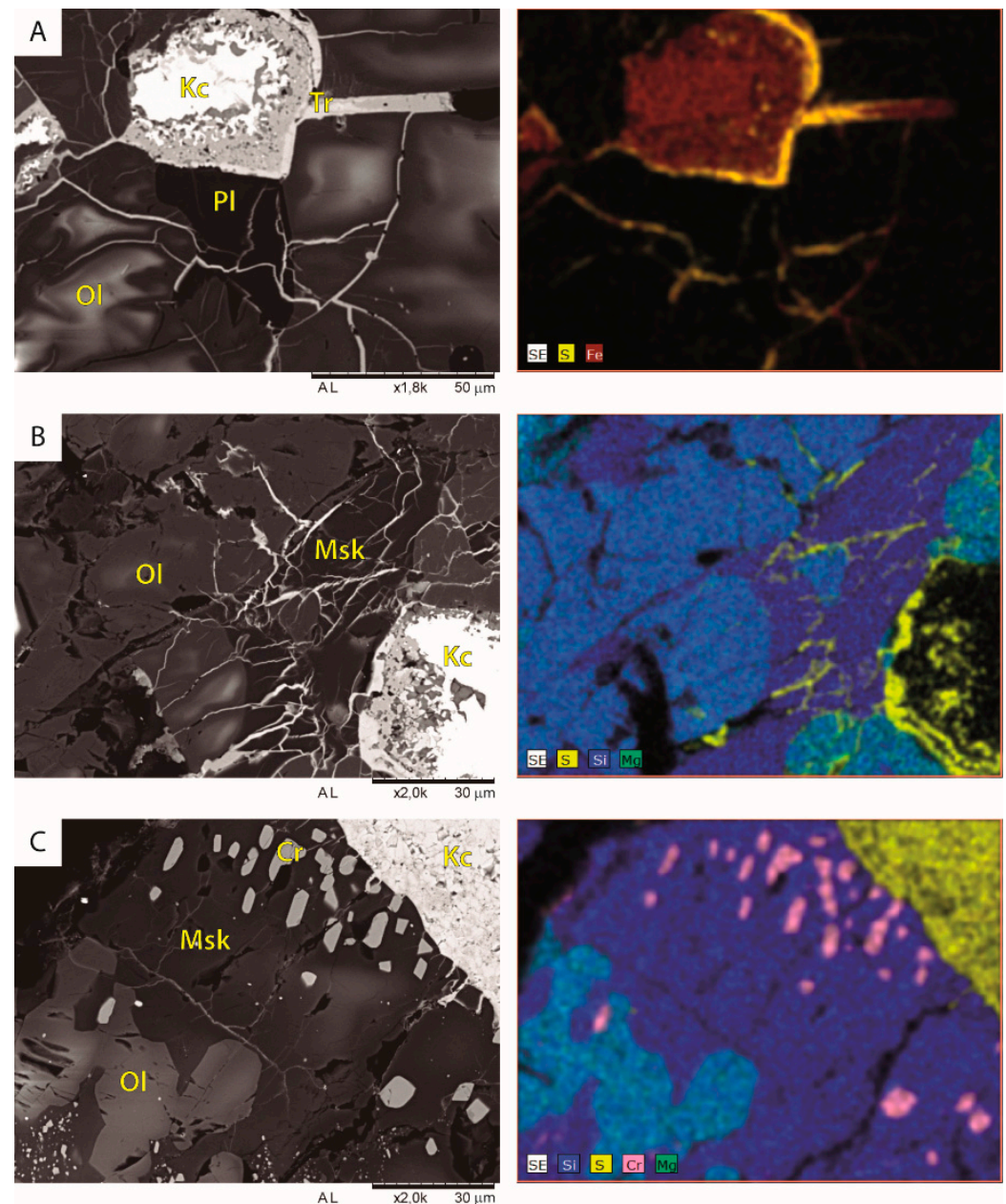

Figure 12. Scanning Electron Microscope images (left) and composition maps (right). (A) Sulfurous veins surrounding a taenite-kamacite grain. (B) Sulfurous veins filling olivine grains, and transformation of taenite-kamacite grains into troilite-pentlandite. (C) Chromite formation by Cr-diffusion from olivine and Fe-alteration of kamacite. Msk: Maskelynite; Ol: Olivine; Tr: Troilite; Kc: Kamacite; Pl: Plagioclase; Cr: Chromite.

Lastly, the final accretion process, after the formation of the solar system, involved the deformation of the clasts under fragile conditions, with the development of planar fissures and pseudotaquilites (Figures 1B and 12C). This process involved a major local increase of both pressure (>10 GPa) and temperature $(>750 \mathrm{~K})$, with the development of minor melt pockets, and locally causes the reequilibrium 
of the olivine with neoformation of chromite (Figure 12C). This diffusion can be related with an increase in the oxidant conditions, as occurs in other meteorites [31], but in this one related with a last phase of acretion (not with a reflection of the earliest traces of the solar system formation, as in reference [32].

\section{Conclusions}

By using non-destructive analytical techniques to study materials preserved in the collections of museums and other institutions, it is possible to obtain better results and a deeper knowledge of the studied objects than with more traditional destructive techniques. In the case of the Cangas de Onís meteorite, FTIR and Raman spectroscopy studies have enabled us to determine the presence of different mineral species and relate these phases to differences in the shock-metamorphic conditions that the material underwent.

Such studies make it possible to determine and interpret the evolutionary history of meteorites with greater precision. In the study of the Cangas de Onís meteorite, we can see that the extent of the metamorphic conditions within one studied sample is heterogeneous, which leads us to believe that the last accretionary event that took place in this regolithic breccia was not significant enough to allow for overall homogenization. All of this serves to demonstrate that these methods can enable us to classify meteorites according to the classic scheme while using techniques that are not only quick and affordable, but most importantly are non-destructive as well. In addition, the spectral variations observed in this study can be useful to interpret and model remotely sensed spectra of planetary and asteroidal surfaces (e.g., reference [33]).

Supplementary Materials: The following are available online at http://www.mdpi.com/2075-163X/9/7/417/s1, Table S1: Apatite EPMA; Table S2: Merrillite EPMA; Table S3: Plagioclase EPMA.

Author Contributions: Conceptualization, A.R.-O. and O.G.-M.; Methodology, A.R.-O., O.G.-M. and J.G.-G.; Resources, L.M.R.T., J.G.-G. and L.T. Writing-Original Draft Preparation, A.R.-O. and O.G.-M.; Writing-Review \& Editing, A.R.-O. and O.G.-M.; Supervision, A.R.-O. and O.G.-M.

Funding: Financial support was provided by Researches Projects UNOV-13-EMERGENTE-17 and UNOV-12-MB-04 from the University of Oviedo.

Conflicts of Interest: The authors declare no conflict of interest.

\section{References}

1. Thompson, R.M.; Xie, X.; Zhai, S.; Downs, R.T.; Yang, H. A comparison of the $\mathrm{Ca}_{3}\left(\mathrm{PO}_{4}\right)_{2}$ and $\mathrm{CaSiO} 3$ systems, with a new structure refinement of tuite synthesized at $15 \mathrm{GPa}$ and $1300^{\circ} \mathrm{C}$. Am. Mineral. 2013, 98, 1585-1592. [CrossRef]

2. Xie, X.; Zhai, S.; Chen, M.; Yang, $\mathrm{H}$. Tuite, $\gamma-\mathrm{Ca}_{3}\left(\mathrm{PO}_{4}\right)_{2}$, formed by chlorapatite decomposition in a shock vein of the Suizhou 16 chondrite. Meteorit. Planet. Sci. 2013, 48, 1515-1523. [CrossRef]

3. Zhai, S.; Wu, X.; Ito, E. High-pressure raman spectra of tuite, $\gamma-\mathrm{Ca}_{3}\left(\mathrm{PO}_{4}\right)_{2}$. J. Raman Spectrosc. 2010, 41, $1011-1013$. [CrossRef]

4. Zhai, S.; Liu, A.; Xue, W.; Song, Y. High-pressure raman spectroscopic studies on orthophosphates $\mathrm{Ba}_{3}\left(\mathrm{PO}_{4}\right)_{2}$ and $\mathrm{Sr}_{3}\left(\mathrm{PO}_{4}\right)_{2}$. Solid State Commun. 2011, 151, 276-279. [CrossRef]

5. Zhai, S.; Yamazaki, D.; Xue, W.; Ye, L.; Xu, C.; Shan, S.; Ito, E.; Yoneda, A.; Yoshino, T.; Guo, X.; et al. PVT relations of $\gamma-\mathrm{Ca}_{3}\left(\mathrm{pPO}_{4}\right)_{2}$ tuite determined by in situ X-ray diffraction in a large-volume high-pressure apparatus. Am. Mineral. 2013, 98, 1811-1816. [CrossRef]

6. Litasov, K.D.; Podgornykh, N.M. Raman spectroscopy of various phosphate minerals and occurrence of tuite in the Elga IIE iron meteorite. J. Raman Spectrosc. 2017, 48, 1518-1527. [CrossRef]

7. Moroz, T.N.; Goryainov, S.V.; Pokhilenko, N.P.; Podgornykh, N.M. Crystalline and Amorphous Matter in the Chelyabinsk Meteorite: Evidence from Raman Spectroscopy. Dokl. Earth Sci. 2014, 457, 831-834. [CrossRef]

8. Johnson, J.R.; Hörz, F. Visible/near-infrared spectra of experimentally shocked plagioclase feldspars. J. Geophys. Res. Planets 2003, 108, 5120. [CrossRef]

9. Liu, L.-G.; El Gorsey, A. High-pressure phase transitions of the feldspars, and further characterization of lingunite. Int. Geol. Rev. 2007, 49, 854-860. [CrossRef] 
10. Glotch, T.D.; Wright, S.P.; McKeeby, B.E.; Ferrari, M.J. Micro-FTIR and micro-Raman spectroscopy of shocked basalts from Lonar crater, India. In Proceedings of the 42nd Lunar and Planetary Science Conference, Woodlands, TX, USA, 7-11 March 2011.

11. Koch-Müller, M.; Mrosko, M.; Gottschalk, M.; Schade, U. Pressure-induced phase transitions in ilvaite studied by in situ micro-FTIR spectroscopy. Eur. J. Mineral. 2012, 24, 831-838. [CrossRef]

12. Jaret, S.J.; Glotch, T.D.; Wright, S.P. Micro-FTIR and Micro-Raman Spectroscopy of a Shocked Basalt from the Lonar Crater, India. In Proceedings of the Lunar and Planetary Institute Science Conference Abstracts, Woodlands, TX, USA, 18-22 March 2013; Volume 44, p. 2881.

13. Fritz, J.; Greshake, A.; Fernandes, V.A. Revising the shock classification of meteorites. Meteorit. Planet. Sci. 2017, 52, 1216-1232. [CrossRef]

14. Luanco, J.R. Descripción y análisis de los aerolitos que cayeron en el distrito de Cangas de Onís (Asturias). An. Soc. Española Hist. Nat. 1874, 3, 69-95.

15. Graf, T.; Caffee, M.W.; Marti, K.; Nishiizumi, K.; Ponganis, K.V. Dating collisional events: ${ }^{36} \mathrm{Cl}-{ }^{36}$ Ar exposure ages of H-chondritic metals. Icarus 2001, 150, 181-188. [CrossRef]

16. Leya, I.; Graf, T.; Nishiizumi, K.; Wieler, R. Cosmic-ray production rates of helium, neon and argon isotopes in $\mathrm{H}$ chondrites based on chlorine-36/argon-36 ages. Meteorit. Planet. Sci. 2001, 36, 963-973. [CrossRef]

17. Williams, C.V.; Keil, K.; Taylor, G.J. Breccia within breccia in the Cangas de Onis regolith breccia: Implications for the history of the $\mathrm{H}$ chondrite parent body regolith. Chem. Der Erde 2000, 60, 269-278.

18. Williams, C.V.; Rubin, A.E.; Keil, K.; Miguel, A.S. Petrology of the Cangas de Onis and Nulles regolith breccias: Implication for parent body history. Meteoritics 1985, 20, 331-345.

19. Rubio-Ordóñez, A.; Cárdenes, V.; Rodríguez-Terente, L.; Tormo, L.; García-Guinea, J. Backscattered electron images, cathodoluminescence, and raman spectroscopy study of phosphates and maskelynite from the H6 Cangas de Onís regolith breccia. Spectrosc. Lett. 2012, 45, 135-140. [CrossRef]

20. Garcia-Guinea, J.; Tormo, L.; Rubio-Ordoñez, A.; Garcia-Moreno, O. Non-destructive analyses on a meteorite fragment fell in the Madrid city centre at 1896. Talanta 2013, 114, 152-159. [CrossRef]

21. Jolliff, B.L.; Hughes, J.M.; Freeman, J.J.; Zeigler, R.A. Crystal chemistry of lunar merrillite and comparison to other meteoritic and planetary suites of whitlockite and merrillite. Am. Mineral. 2006, 91, 1583-1595. [CrossRef]

22. Fritz, J.; Greshake, A.; Stöffler, D. Micro-raman spectroscopy of plagioclase and maskelynite in martian meteorites: Evidence of progressive shock metamorphism. Antarct. Meteor. Res. 2005, 18, 96-116.

23. Destainville, A.; Champion, E.; Bernache-Assollant, D.; Laborde, E. Synthesis, characterization and thermal behavior of apatitic tricalcium phosphate. Mater. Chem. Phys. 2003, 80, 269-277. [CrossRef]

24. Essehli, R.; El Bali, B.; Benmokhtar, S.; Fuess, H.; Svoboda, I.; Obbade, S. Synthesis, crystal structure and infrared spectroscopy of a new non-centrosymmetric mixed-anion phosphate $\mathrm{Na}_{4} \mathrm{Mg}_{3}\left(\mathrm{PO}_{4}\right)_{2}\left(\mathrm{P}_{2} \mathrm{O}_{7}\right)$. J. Alloy. Compd. 2010, 493, 654-660. [CrossRef]

25. Hughes, J.M.; Jolliff, B.L.; Gunter, M.E. The atomic arrangement of merrillite from the Fra Mauro Formation, Apollo 14 Lunar mission: The first structure of merrillite from the Moon. Am. Mineral. 2006, 91, 1547-1552. [CrossRef]

26. Stavrou, E.; Tatsi, A.; Salpea, E.; Boulmetis, Y.C.; Kontos, A.G.; Raptis, Y.S.; Raptis, C. Raman study of zircon-structured $\mathrm{rPO}_{4}(\mathrm{r}=\mathrm{Y}, \mathrm{Tb}, \mathrm{Er}, \mathrm{Tm})$ phosphates at high pressures. J. Phys. Conf. Ser. 2008, 121, 042016. [CrossRef]

27. Tatsi, A.; Stavrou, E.; Boulmetis, Y.C.; Kontos, A.G.; Raptis, Y.S.; Raptis, C. Raman study of tetragonal TbPO and observation of a first-order phase transition at high pressure. J. Phys. Condens. Matter 2008, 20, 425216. [CrossRef]

28. Mrosko, M.; Koch-Müller, M.; Schade, U. In-situ mid/far micro-FTIR spectroscopy to trace pressure-inducted phase transitions in strontium feldpsar and wadsleyite. Am. Mineral. 2011, 96, 1748-1759. [CrossRef]

29. Wright, S.P.; Christensen, P.R.; Sharp, T.G. Laboratory thermal emission spectroscopy of shocked basalt from Lonar crater, India, and implications for mars orbital and sample data. J. Geophys. Res. Planets 2011, 116, E09006. [CrossRef]

30. Bischoff, A.; Stöffler, D. Shock metamorphism as a fundamental process in the evolution of planetary bodies: Information from meteorites. Eur. J. Mineral. 1992, 4, 707-756. [CrossRef]

31. Schmidt, B.C.; Holtz, F.M.; Bény, J.M. Incorporation of $\mathrm{H}_{2}$ in vitreous silica, qualitative and quantitative determination from Raman and Infrared spectroscopy. J. Non-Cryst. Solids 1998, 240, 91-103. [CrossRef] 
32. Weinbruch, S.; Palme, H.; Müller, W.F.; El Goresy, A. FeO-rich rims and veins in Allende forsterite: Evidence for high temperature condensation at oxidizing conditions. Meteoritics 1990, 25, 115-125. [CrossRef]

33. Moroz, L.; Schade, U.; Wäsch, R. Reflectance Spectra of Olivine-Orthopyroxene-Bearing Assemblages at Decreased Temperatures: Implications for Remote Sensing of Asteroids. Icarus 2000, 147, 79-93. [CrossRef] 